\title{
Short- and long-term dietary effects on disease and mortality in American lobster Homarus americanus
}

\author{
Michael F. Tlusty*, Anna Myers, Anita Metzler
}

New England Aquarium, Central Wharf, Boston, Massachusetts 02110, USA

\begin{abstract}
The American lobster Homarus americanus fishery is heavily dependent on the use of fish as bait to entice lobsters into traps. There is concern that this food supplementation is nutritionally insufficient for lobsters, but previous experiments reported conflicting results. We conducted a long-term feeding experiment in which $1 \mathrm{yr}$ old American lobsters were fed one of 7 diets for a period of $352 \mathrm{~d}$, a time that allowed the lobsters to molt thrice. The diets consisted of fresh frozen herring, a 'wild' diet (rock crab, mussel, and Spirulina algae), a formulated artificial diet for shrimp, paired combinations of these 3 diets or a diet formulated at the New England Aquarium (Artemia, fish and krill meal, Spirulina algae, soy lecithin, vitamins and minerals). The lobsters fed the diet of $100 \%$ fish had higher initial molting rates, but within the period of this experiment all either contracted shell disease or died. Mixed diets resulted in higher survival and a lower probability of mortality. This research demonstrated a critical time component to diet studies in lobsters. Short- and long-term impacts of diet differ. In the long term, continual high consumption rates of fish by the lobsters promote poor health in all lobsters, not just those of market size. The use of fish as bait may make lobsters more susceptible to the stress associated with environmental fluctuation, thereby leading to increased disease and mortality. This nutritional stress can be used to develop a laboratory model of shell disease in American lobsters.
\end{abstract}

KEY WORDS: American lobster $\cdot$ Bait $\cdot$ Diet $\cdot$ Herring $\cdot$ Shell disease $\cdot$ Laboratory model Resale or republication not permitted without written consent of the publisher

\section{INTRODUCTION}

The American lobster fishery provides significant economic benefits to coastal communities along eastern North America. The fisheries in Canada and the USA are valued, respectively, at US\$525 and US\$365 million annually (DFO 2006, Kerns 2006), with actual economic impact being 4.5 times greater (Nicosia \& Lavalli 1999). In addition to its economic importance, the American lobster plays a critical role in the ecology of the western Atlantic. Lobsters are large mobile predators that affect the structure of benthic communities (Ojeda \& Dearborn 1991).

In the past 2 decades, lobster harvests have increased in quantity and value while stocks of most Gulf of Maine groundfish species and some invertebrates (such as the northern shrimp Pandalus borealis) have been severely reduced due to overfishing (Northeast Fisheries Science Center 2004). It is likely that the significant increase in landings and abundance of the American lobster in recent years is associated with the use of bait in the lobster industry (Saila et al. 2002, Grabowski et al. 2005). In Maine, fishers use about 99790 t herring $\mathrm{yr}^{-1}$ as bait (New England Fisheries Management Council 1999) to land approximately $27215 \mathrm{t}$ of lobster (Kerns 2006). This use of bait amounts to an organic energy subsidy equivalent to approximately 1.8 times the natural primary production of the coastal ecosystem (Saila et al. 2002). Lobsters are using bait as a significant food source. The gut contents of lobsters contain approximately $80 \%$ bait (R. Steneck pers. comm.), and isotope analysis indicates approximately $70 \%$ of a lobster's tissue is derived from bait (Grabowski et al. 2005). The use of 
bait is so pervasive that many fishers claim that wild lobsters have essentially been 'cultured' through food supplementation (Saila et al. 2002).

If a lobster's diet is comprised largely of bait, then it is critical that this food is of sufficient quality to maintain lobster health. A number of studies has assessed the adequacy of fish as a dietary component. Some studies showed that lobsters fare well when fed fish. Donahue et al. (1998) found that lobsters held in pounds and fed cod for $38 \mathrm{~d}$ had better shell quality and weight gain than those fed artificial diets. Likewise, Grabowski et al. (2005) observed that lobsters from fished areas that consumed bait as a diet component) grew more over a month than lobsters from unfished areas (no bait in the diet). Other evidence suggests that fish may not be an appropriate diet for lobsters in the long term. Lobster caught using thawed mackerel were 7 times more likely to be graded 'weak' at the processing stage than lobsters landed using other bait types (Lavallee et al. 2000). Prince et al. (1995) found a higher incidence of shell disease when market-size lobsters were fed bait items as opposed to artificial diets. Likewise, Stewart et al. (1967) found that a diet consisting only of herring significantly depressed serum protein values, an indication of physiological stress.

These studies were all conducted on adult lobsters, and unfortunately, the pre-experimental histories of the subjects were unknown. Prince \& Bayer (2005) observed that lobsters from certain areas had a higher probability of getting impoundment shell disease than to those from other areas. Thus, lobsters may differ in parameters such as prior stress experiences that could affect disease susceptibility and survival when presented with a change in diet. Without accounting for these differences, feeding studies of wild-caught animals will not adequately assess how diet influences lobster health and survival. In addition, these earlier studies were relatively brief for lobsters. Major growth events in lobsters are dictated by the molting process, which occurs once a year in adults. Molting in lobsters is an energetically taxing event, as it is the point at which nutritional stress may take a large toll. The time span of the studies cited above are on the order of months, significantly less than the length of a molt interval.

To address the short- and long-term impacts of bait consumption by lobsters, survival and disease state of $1 \mathrm{yr}$ old hatchery-reared juvenile lobsters were assessed during a year-long laboratory feeding study. Using hatchery-reared juvenile lobsters as test subjects has several advantages. First, they are all siblings, and have all been reared similarly (temperature and diets). Though they are not yet reproductively mature, vagile juveniles (25 to $40 \mathrm{~mm}$ carapace length, approx- imately 2 yr old) are physiologically identical to adults in every other respect (Lawton \& Lavalli 1995). Adult lobsters molt only once a year or less, making it difficult to study factors such as growth and frequency of molting without significant time investment. Vagile juveniles, on the other hand, molt 3 times per year or more. Furthermore, vagile juveniles consume $10 \%$ of their body weight daily, versus just $1 \%$ in adult lobsters (D'Abramo \& Conklin 1985), potentially making the diet composition of juveniles more important. Finally, with respect to the issue of bait consumption, vagile juveniles spend more time in traps than adult lobsters, and thus the potential impact of bait consumption may be more significant on this size class of lobster (Jury et al. 2001).

\section{MATERIALS AND METHODS}

Sibling lobsters were hatched and reared to an age of 420 to $450 \mathrm{~d}$ at the New England Aquarium, then randomly divided into 7 groups (each receiving a different diet) of 40 lobsters. The 7 diets were a $100 \%$ fresh frozen herring diet $(\mathrm{H})$, a 'wild' diet (W, $48 \%$ rock crab, $48 \%$ mussel, and $4 \%$ Spirulina), a formulated artificial diet for shrimp (A, Progression 3, Salt Creek), paired combinations of these 3 diets (WA, HA, HW) or a hatchery diet $(\mathrm{N})$. The $\mathrm{N}$ diet was developed at the New England Aquarium over several years (Tlusty et al. 2005), and consisted of $4.6 \%$ frozen adult Artemia, $19.9 \%$ krill meal, $19.9 \%$ fish meal, $15.9 \%$ soy lecithin, $7.9 \%$ kelp meal, $6.3 \%$ Spirulina, 20.5\% vitamin/ mineral/bone meal mix, and $0.01 \%$ astaxanthin. The $\mathrm{H}$ and $\mathrm{W}$ diets were first blended into a slurry, then all diets were bound with $75 \mathrm{ml}$ of hot dissolved gelatin per $150 \mathrm{~g}$ blended ingredients to create a water-stable block of food. The lobsters were held in individual containers and fed once per day. Excess food was removed after a minimum of $4 \mathrm{~h}$. Each day, lobsters were censused and examined for molting and presence of shell disease (degradation of the outer cuticle).

All lobsters were held individually in $71 \mathrm{~cm}^{2}$ round mesh containers (RN 3531, InterNet). These containers were held within the same tray, and thus, although grouped by diet, all lobsters were in aquatic contact. The seawater in the facility was brought in from Boston Harbor, filtered, UV sterilized and tested weekly in order to maintain 30.5-34 salinity, $\mathrm{pH} 7.84-7.97$, and $\mathrm{NH}_{4}{ }^{+}<70 \mathrm{ppm}$, and $15^{\circ} \mathrm{C}$. All trays and containers containing lobsters were regularly cleaned and siphoned. Lobsters were provided $12 \mathrm{~h}$ of wide spectrum fluorescent light per day.

All lobsters presenting shell disease in this study had $1-10 \%$ coverage, and thus gradations were assessed within this category. The number of minor lesions 
( $<2 \mathrm{~mm}$ ) was counted, while those lesions $>2 \mathrm{~mm}$ were scored as 2 minor lesions. The lesions were indexed from 1 (1 to 2 lesions) to 5 (>9 lesions). Lobsters remained on the diets for $352 \mathrm{~d}$. In assessing the severity of shell disease, the lobsters fed diet $\mathrm{N}$ were omitted from analysis because too few of them exhibited shell disease, thus invalidating statistical tests. Shell samples from 4 lobsters (from Treatments A, WA, HA, HW) were sent to Idexx Laboratories, where they were tested for surficial bacteria using a Vitek (bioMérieux, Durham) automated bacterial identification and antibiotic susceptibility testing system.

Survival and disease data over time were analyzed using a Gehan-Breslow survival analysis with multiple comparisons performed using the Holm-Sidak method (SigmaStat 3.0, Systat). When analyzing disease, healthy lobsters were categorized as 'survivors', while lobsters with shell disease were classified as 'deaths'. These data were also analyzed graphically using a ternary plot (Fig. 1). This plot assumes that there are 3 discrete states: healthy, diseased, or moribund. A point at the top vertex of the triangle would represent $100 \%$ healthy lobsters, with none in the treatment being diseased or dead. The bottom-left vertex represents $100 \%$

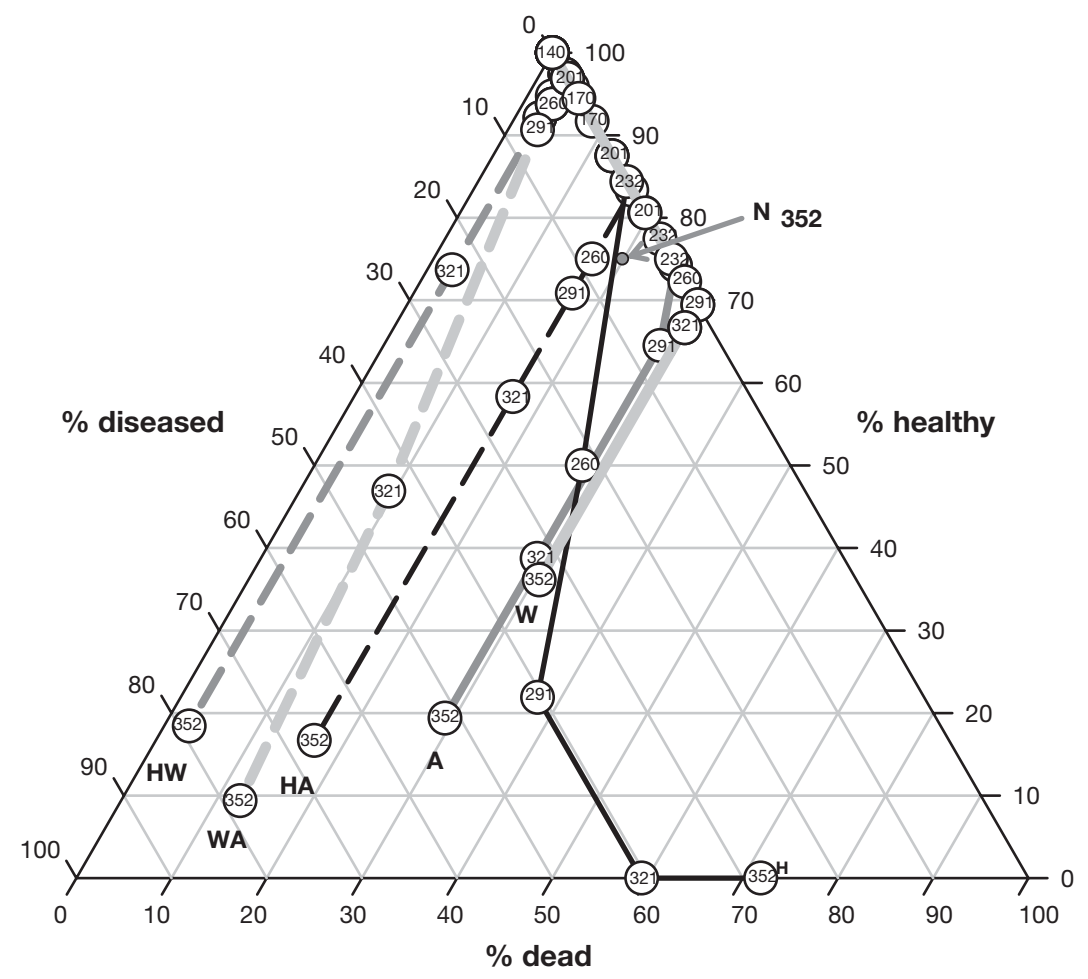

Fig. 1. Homarus americanus. Categorical status (healthy, shell diseased, dead) of American lobsters fed 1 of 7 experimental diets over $352 \mathrm{~d}$ (in circles). Diet components are herring $(\mathrm{H})$, crab and mussel (W), commercial shrimp feed (A), or a prepared diet $(\mathrm{N})$. Samples near the top vertex are healthy. The incidence of disease increases as points move toward the left lower vertex, while mortality increases as they move toward the right lower vertex diseased lobster in the treatment, while the right-bottom vertex represents $100 \%$ mortality. Among continuous data sets, those with normal distributions were analyzed without transformation, while non-normal data were first ranked, and then analyzed using a 1-way non-parametric (Kruskal-Wallis) ANOVA (Zar 1984). Pairwise comparisons were made using Tukey's (normal data) or Dunn's (non-normal data) tests.

\section{RESULTS}

Diet had a significant impact on both health and survival of 1 yr old American lobsters. The N-fed lobsters had the highest survival and the lowest disease incidence, while the $\mathrm{H}$-fed lobsters had the lowest survival (Gehan-Breslow statistic $=57.1, \mathrm{df}=6, \mathrm{p}<0.001$, Fig. 1), and the highest disease incidence (GehanBreslow statistic $=66.8 . \mathrm{df}=6, \mathrm{p}<0.001$, Fig. 1). Vibrio algynolyticus, was identified from the lesions on 4 separate lobsters, and was presumed to have initiated all cases of shell disease. Combining the disease and survival data in a ternary plot (Fig. 1) demonstrated that the 3 mixed diets clustered together near the lower left vertex indicating high disease, and low mortality. This diagram also demonstrates how the $\mathrm{N}$ - and $\mathrm{H}$-fed lobsters were most different from those fed the other diets. By the end of the experiment all $\mathrm{H}$-fed lobsters were classified as either diseased or dead, and this observation is of considerable consequence. On the other hand, the $\mathrm{N}$-fed lobsters had the lowest incidences of disease or mortality.

Diet had a significant effect on the number of molts (Kruskal-Wallis 1way ANOVA, df $=6, H=63.23, \mathrm{p}<$ $0.001)$ and the intermolt period (Kruskal-Wallis 1-way ANOVAs, df = 6 , intervals $1-2$ and $2-3, H=38.67$ and 17.23 , respectively, $\mathrm{p}<0.001$ and $<0.01$, respectively). Lobsters consuming the H, HW and WA diets had the most molts (mean \pm SE was $3.1 \pm$ $0.12,2.8 \pm 0.21$, and $2.7 \pm 0.17$, respectively) compared to those fed W (1.6 \pm 0.22). For lobsters molting at least twice during the experiment, those fed N, H, HW, and WA had the shortest intermolt intervals $(70.0 \pm 2.55$, $75.1 \pm 4.7,80.0 \pm 4.4$, and $91.2 \pm 7.2 \mathrm{~d}$, respectively). HW and WA were statistically clustered (Dunn's Method, $\mathrm{p}<0.05)$ with all other diets. Within 
this group, HA had the longest intermolt interval of $105.8 \pm 8.7$ d. For lobsters molting 3 times, those fed $\mathrm{H}$ had a significantly shorter intermolt interval (Dunn's Method, $\mathrm{p}<0.05,72.7 \pm 4.3 \mathrm{~d})$ than those fed HA $(91.5 \pm 5.5)$. All other diets were intermediate to, and not significantly different from, these extremes.

Lobsters fed diets $\mathrm{A}$ and $\mathrm{H}$ had significantly more lesions ( 7 to 8 lesions) than those fed other diets (1-way ANOVA, $\left.F_{5,54}=10.61, \mathrm{p}<0.001\right)$. However, the lobsters that died during the course of the experiment did not have significantly higher incidence of shell disease than lobsters that survived (Mann-Whitney Rank Sum Test, $\mathrm{p}>0.60$ ).

\section{DISCUSSION}

Overall, these results indicate that the short-term implications of fish consumption were positive in that the intermolt interval was shortest for lobsters eating a $100 \%$ fish diet. However, in the long term, the lobsters fed the $100 \%$ fish diet had a disease-mortality trajectory that was different from all other diets, and by the end of the experiment, none of these lobsters were classified as healthy. This appears to be a cumulative effect of being fed an insufficient diet. Prior to the experiment, the lobsters were fed the $\mathrm{N}$ diet, which appeared to provide adequate nutrition (given the low levels of disease and mortality over the course of the experiment). When the lobsters were switched to experimental diets, the continued feeding of these diets caused the lobsters to progressively diverge from healthy into their final diseased/moribund state.

The health problems associated with the long-term consumption of a fish diet suggests that it is nutritionally insufficient to adequately maintain lobsters. This 'nutritional insufficiency' must be placed in context of the greater initial growth rate of the lobsters fed the $\mathrm{H}$ diet. The rapid growth may have exacerbated the onset of shell disease through a structural deficiency, or through a decreased ability to respond to bacterial infections. A second possibility is that there was a disease agent present in the fish diet. However, evidence does not support this, as the lobsters fed the $50 \%$ fish diets did not display a significant disease state. Furthermore, all lobsters were held in the same volume of water, and this aquatic contact should have facilitated the spread of disease were the fish diets were acting as an innoculum. Finally, Vibrio algynolyticus, which is responsible for impoundment shell disease in other crustaceans (Shields et al. 2006), was present in lesions of lobsters fed diets not containing fish.

This experiment may offer an explanation for the contradictory results of previous studies. Essentially, the results of short-term $(<1$ molt cycle, e.g. Donahue et al. 1998, Grabowski et al. 2005) feeding trials are dependent on the initial condition of the lobsters entering the experiment. If lobsters are healthy and not physically or nutritionally stressed, then fish is likely to be an adequate short-term diet. However, when lobsters are physically or nutritionally stressed, the consumption of fish will exacerbate this prior stress, resulting in a diseased or moribund state (Prince \& Bayer 2005). In our experiment, it took many molts for lobsters to finally become susceptible to shell disease.

The present study demonstrated that fish used as bait can facilitate shell disease when consumed in high quantities. We also showed that lobsters fed a mixed diet containing $50 \%$ fish had significantly reduced mortality rates compared to those fed $100 \%$ fish. What is not known is whether there is a linear, cusp catastrophic (Mangel 2006) or another non-linear relationship between health and fish inclusion in the diet. If lobsters are foraging optimally and integrate between 20 and $30 \%$ of non-bait items into their diet (Grabowski et al. 2005, R. Steneck pers. comm.), then this relationship is likely to be non-linear. Consequently, it will be important to elucidate the foraging rules to which lobsters adhere. If lobsters opportunistically consume fish as it is presented to them in traps, then the relationship between health and fish inclusion in the diet need not necessarily be non-linear, and the shape of this relationship should be determined. In either case, there is a concern that the foraging behavior lobsters follow is insufficient to keep them healthy in the long term either under prevailing conditions, or when there is environmental stochasticity. If lobsters consume a diet that is sufficient in one environment, but not in another, then any change from prevailing conditions will push them into a state where the diet is suboptimal, and their health will decline. Such changes in prevailing environmental conditions could include diet shifts, but may also include temperature changes or anoxia (Glenn \& Pugh 2006).

While this is not the first study to determine that lobsters fed a $100 \%$ fish diet have increased rates of disease and mortality, it places this nutritional stress in a temporal context related to the lobster's molt cycle. In the short term, a $100 \%$ fish diet appears to lead to increased growth, particularly in lobsters that are of an adequate physical condition. However, in the long term, or for lobsters that are not of an adequate physical condition, a $100 \%$ fish diet will lead to increased health problems, including shell disease. If the nutritional stress is severe or long enough, this will increase mortality. The ability to manipulate disease through diet creates an opportunity to develop a laboratory model for shell disease in this species. Shell disease has recently increased in prevalence and geographic distribution (Glenn \& Pugh 2006), leading to significant eco- 
nomic losses. Controlled studies of the disease are necessary to understand this disease in American lobsters.

Our experiment demonstrated that juvenile lobsters, although not the target of the fishery, can be impacted by the fishery practices. Sub-legal sized lobsters consume approximately $25 \%$ of all bait (Saila et al. 2002), and vagile juveniles may also spend more time in traps than adult lobsters, increasing the likelihood that they will consume bait (Jury et al. 2001). Thus, while the copious amounts of bait used in this fishery may be feeding the lobsters (Grabowski et al. 2005), it may also be promoting poor health in all lobsters, not just those of market size. Furthermore, if lobsters are preferentially eating bait as opposed to their natural prey, this may have large ramifications for the ecosystem processes in the Gulf of Maine. If predation by lobsters organizes the structure of benthic communities, then removal of this pressure may significantly alter community structure (Ojeda \& Dearborn 1991). Thus, in addition to altering resource flow in the Gulf of Maine (Saila et al. 1992), the use of bait by lobster fishers may have a more direct impact on lobster populations through health and survival.

Acknowledgements. This work was supported by the Darden Environmental Trust, and we thank G. Williams for his assistance with funding. L. Wills of Idexx conducted the microbial analyses, and comments by J. Ayers, R. Cawthorn, B. Rosengaus and 2 anonymous reviewers greatly improved the clarity of this paper. L. Cooke provided editorial assistance. We also thank numerous interns that provided care for the lobsters during this study. Lobsters were maintained in accordance with NEAq ACUC protocol \# 06-01.

\section{LITERATURE CITED}

D'Abramo LR, Conklin DE (1985) Lobster aquaculture. In: Hunter JV, Brown ED (eds) Crustacean and mollusk aquaculture in the United Stares. AVI Publishing, Westport, MA, p 159-201

DFO (2006) 2004 value of Atlantic coast commercial landings, by region. Available at: www.dfo-mpo.gc.ca/communic/ statistics/commercial/landings/seafisheries/s2004av_e.htm (accessed Dec 21, 2006)

Donahue DW, Bayer RC, Riley JG (1998) Effects of diet on weight gain and shell hardness of new-shell American lobster, Homarus americanus. J Appl Aquac 8:79-85

Glenn R, Pugh TL (2006) Epizootic shell disease in American lobster (Homarus americanus) in Massachusetts coastal waters: interactions of temperature, maturity, and intermolt duration. J Crustac Biol 26:639-660

Grabowski JH, Clesceri EJ, Yund PO, Weber M, Poland P, Myrick M (2005) Are we using herring to farm lobsters? The effect of herring bait on lobster growth, and the fate of discarded bait on bottom habitat. Northeast Consortium Final Report 02-566. Northeast Consortium, Durham, NH
Jury SH, Howell WH, O'Grady DF, Watson WH (2001) Lobster trap video: in situ video surveillance of the behavior of Homarus americanus in and around traps. Mar Freshw Res 52:1125-1132

Kerns T (2006) Species highlight: American lobster. Atlantic States Marine Fisheries Commission. Available at: www. asmfr.org/speciesDocuments/lobster/ASMFCLobsterFlyer_ web06.pdf (accessed Dec 1, 2006)

Lavallee J Spangler ES, Hammell KL, Dohoo IR, Cawthorn RJ (2000). Analytical assessment of handling, fishing practices, and transportation risk factors on lobster (Homarus americanus) health in Prince Edward Island, Canada. J Shellfish Res 19:275-281

Lawton P, Lavalli KL (1995) Postlarval, juvenile, adolescent, and adult ecology. In: Factor JR (ed) Biology of the lobster Homarus americanus. Academic Press, San Diego, CA, p 47-88

Mangel MS (2006) The theoretical biologist's toolbox. Quantitative methods for ecology and evolutionary biology. Cambridge University Press, Cambridge

New England Fisheries Management Council (1999) Atlantic herring fishery management, incorporating the environmental impact statement and regulatory impact review (including the regulatory flexibility analysis). AFMSC/ NMFS, Saugus, MA. Also available at: www.nefmc. org/herring/fmp/section_1.pdf

Nicosia F, Lavalli KM (1999) Homarid lobster hatcheries: their history and role in research, management and aquaculture. Mar Fish Rev 61:1-57

Northeast Fisheries Science Center (2004) Status of fisheries resources off the Northeastern United States. National Oceanic and Atmospheric Administration. Available at: www.nefsc.noaa.gov/sos/spsyn/species.html (accessed Dec 21, 2006)

Ojeda FP, Dearborn JH (1991) Feeding ecology of benthic mobile predators: experimental analyses of their influence in rocky subtidal communities of the Gulf of Maine. J Exp Mar Biol Ecol 149:13-44

Prince DL, Bayer RC (2005) Are all lobsters created equal? Understanding the role of host susceptibility in the development of shell disease in Homarus americanus. In: Tlusty MF, Halvorson H, Smolowitz R, Sharma U (eds) State of lobster science. Lobster shell disease workshop. New England Aquarium, Boston, MA, p 58-67

Prince DL, Bayer RC, Galagher ML, Subramanyam M (1995) Reduction of shell disease with an experimental diet in a Nova Scotia lobster pound. J Shellfish Res 14: 205-207

Saila SB, Nixon SW, Oviatt CA (2002) Does lobster trap bait influence the Maine inshore trap fishery? North Am J Fish Manag 22:602-605

Shields JD,Stephens FJ, Jones B (2006) Pathogens, parasites, and other symbionts. In: Phillips BF (ed) Lobsters: biology management, aquaculture and fisheries. Blackwell, Oxford, p 146-204

Stewart JE, Cornick JW, Dingle JR (1967) An electronic method for counting lobster (Homarus americanus MilneEdwards) hemocytes and the influence of diet on hemocyte numbers and hemolymph proteins. Can J Zool 45: 291-304

Tlusty MF, Fiore DR, Goldstein JS (2005) Use of formulated diets as replacements for Artemia in the rearing of juvenile lobsters (Homarus americanus). Aquaculture. 250: 781-795

Submitted: January 10, 2007; Accepted: August 29, 2007

Proofs received from author(s): December 11, 2007 